\title{
Pemodelan Kanal Pada Jaringan Area Tubuh Nirkabel Menggunakan Teknologi Bluetooth
}

\author{
Rizal Nur Ibrahim, Wirawan, dan Eko Setijadi \\ Jurusan Teknik Elektro, Fakultas Teknologi Industri, Institut Teknologi Sepuluh Nopember (ITS) \\ Jl. Arief Rahman Hakim, Surabaya 60111 Indonesia \\ e-mail: rizalnuribrahim@mhs.ee.its.ac.id,wirawan@ee.its.ac.id, ekosetijadi@ee.its.ac.id
}

\begin{abstract}
Abstrak-Pada wireless body area network (WBAN), propagasi radio dari node sensor yang berada di permukaan tubuh manusia sangat kompleks dan unik bila dibandingkan dengan lingkungan yang lain karena tubuh manusia memiliki bentuk yang kompleks dan terdiri dari jaringan tubuh manusia yang berbeda-beda. Oleh karena itu, model kanalnya juga berbeda dengan model kanal di lingkungan lain. Telekomunikasi nirkabel pada aplikasi jaringan area tubuh membutuhkan Medium Access Control (MAC) yang dapat beradaptasi, dinamis, dan fleksibel untuk mengatasi berbagai persyaratan aplikasi. MAC yang diusulkan menyesuaikan protokol komunikasi dan parameter yang berdasarkan kepada pencapaian konsumsi daya rendah dan laju data yang tinggi untuk itu dipilih salah satu teknologi komunikasi yang memungkinkan untuk hal ini yaitu Bluetooth. Pada tugas akhir ini akan dilakukan pemodelan kanal pada WBAN untuk mendapatkan bentuk kanal yang sesuai dengan kerakteristik tubuh manusia. Dimana pemodelan kanal ini di fokuskan pada teknologi Bluetooth dengan frekuensi 2,4 GHz. Selain itu, dalam pengerjaannya dilakukan simulasi menggunakan software MATLAB.
\end{abstract}

Kata Kunci-Pemodelan Kanal, WBAN.

\section{PENDAHULUAN}

$\mathrm{S}_{\mathrm{te}}^{\mathrm{s}}$ ISTEM komunikasi masa depan didorong oleh konsep terkoneksi dimanapun dan kapanpun yang mana hal ini juga diterapkan pada bidang kesehatan medis. Komunikasi medis nirkabel membantu pekerjaan manusia dan menggantikan kabel-kabel yang ada di rumah sakit. Salah satu contohnya adalah wireless medical telemetry yang mana memantau jarak jauh kesehatan pasien melalui teknologi radio. Hal ini memberikan mobilitas yang tinggi dan meningkatkan kenyamanan untuk pasien dengan membebaskan mereka dari keharusan untuk terkoneksi dengan peralatan di rumah sakit yang memonitor keadaan mereka. Hal ini meningkatkan kualitas dari pelayanan pasien dan efisiensi dari kemampuan administrasi dari rumah sakit. Lebih lagi, wireless medical telemetry juga memenuhi tujuan dalam menurunkan biaya kesehatan karena dapat memonitor dengan jarak jauh beberapa pasien secara bersamaan. Perkembangan teknologi ini akan menuju ke WBAN.

Dari pemahaman umum mengenai WBAN, dapat dengan jelas diketahui bahwa teknologi komunikasi yang digunakan adalah komunikasi jarak pendek. IEEE 802.15.1 Bluetooth beroperasi pada frekuensi 2,4 GHz ISM, dari $2400 \mathrm{MHz}$ sampai 2483,5 MHz. system tersebut menggunakan skema akses frequency-hopping untuk mencegah interference dan fading. Laju symbolnya adalah 1 Msimbol/detik yang mendukung laju bit sampai $1 \mathrm{Mbit} /$ detik. Contoh, sinyal elektrokardiogram dari masing-masing kanal di digitalisasi pada $360 \mathrm{~Hz}$ dengan resolusi 11 bit dan laju data 3,84 Kbps tiap kanal, sehingga semua kanal pada elektrokardiogram memungkinkan untuk dikirim menggunakan Bluetooth. Selain itu, forward error control (FEC) dan automatic repeat request (ARQ) untuk pentranmisian kembali digunakan sebagai otentikasi untuk memastikan komunikasi yang handal.

Tugas akhir ini menawarkan prosedur untuk mendapatkan model dan karakteristik kanal untuk WBAN yang berdasarkan pada parameter kanal dari pengukuran.

\section{DASAR TEORI}

\section{A. Wirelesss Body Area Network}

Body Area Network (BAN) adalah sebuah jaringan yang terdiri dari node heterogen yang dapat merasakan, menggerakkan, melakukan perhitungan, dan berkomunikasi antara satu dengan yang lain melalui kanal nirkabel. BAN mengambil, memproses, dan menyimpan data-data fisiologis (seperti electrocardiogram (ECG) dan tekanan darah), aktivitas (seperti berjalan, berlari, dan tidur), dan lingkungan (seperti suhu, kelembapan, dan adanya zat allergen) dari tubuh manusia dan lingkungan sekitarnya, bahkan juga dapat melakukan pengobatan langsung (pengiriman obat) melalui data yang didapat. BAN dapat sangat berguna dalam membantu tenaga medis professional untuk melakukan keputusan apa saja yang bersangkutan dengan pengobatan pasien dengan cara memberikan informasi yang kontinyu mengenai kondisi pasien.

BAN termasuk kedalam wireless sensor network (WSN). Pada awalnya, BAN berkembang dari wireless personal area network (WPAN) yang kemudian berkembang ke dunia medis yaitu seperti pulse oximeters dan retina prostetik yang dipasang di tubuh manusia dan terkoneksi melalui kanal wireless. Di rumah sakit, BAN di koneksikan dengan perlalatan rumedis lainnya seperti monitor Holter dan perekam data medis untuk membentuk sebuah jaringan alat medis untuk pasca-operasi atau untuk memonitoring pasien ICU.

Sensor merupakan hal yang penting dan terdapat berbagai bentuk, sensor pada BAN memiliki beberapa sifat penting sebegai berikut. 

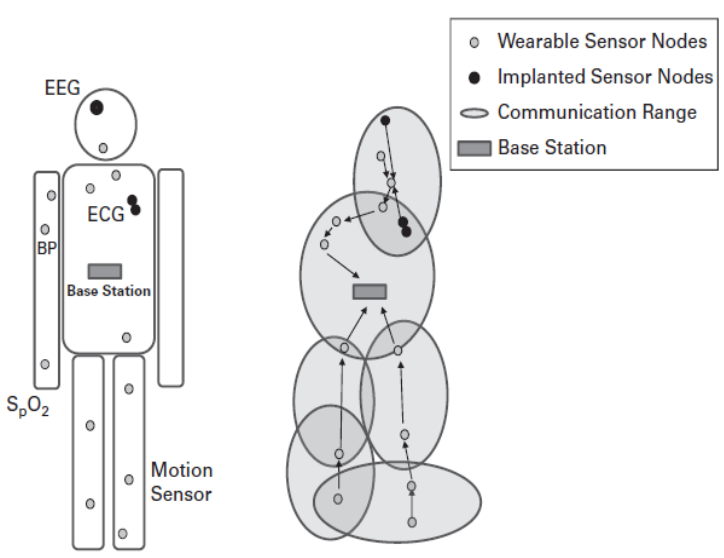

Gambar 1. Lokasi Node Sensor Pada Tubuh

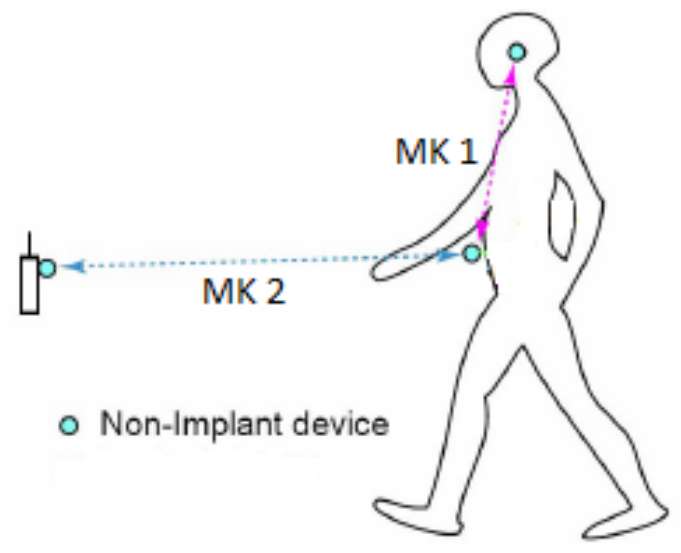

Gambar 2. Link komunikasi yang memungkinkan pada WBAN dengan frekuensi $2.4 \mathrm{GHz}$ (Bluetooth).

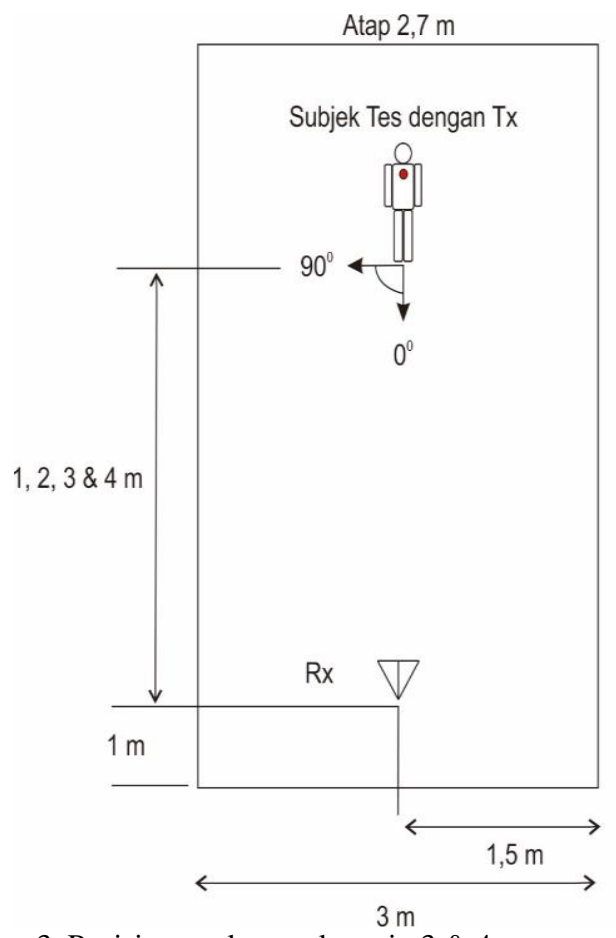

Gambar 3. Posisi pengukuran skenario $3 \& 4$

$5,5 \mathrm{~m}$

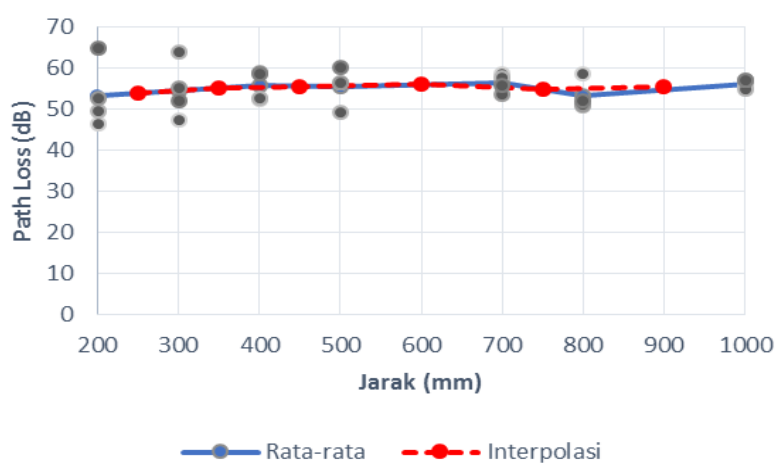

Gambar 4. Nilai Path loss vs Jarak dalam empat kali pengukuran

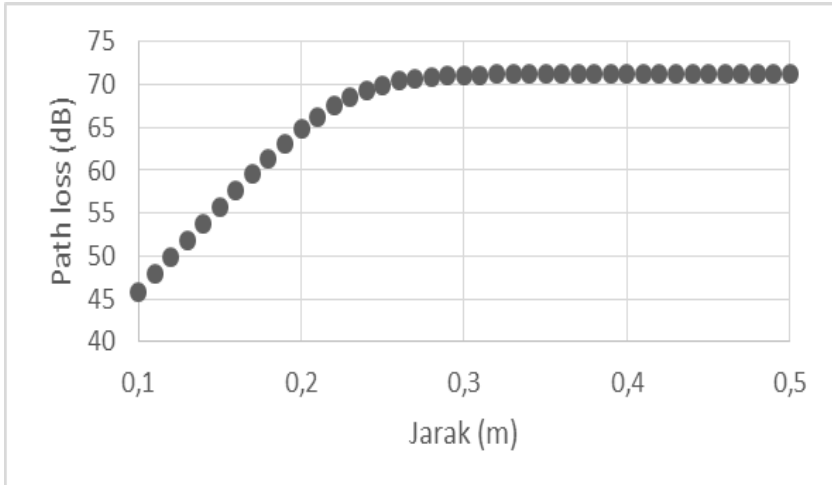

Gambar 5. Nilai Path loss vs Jarak

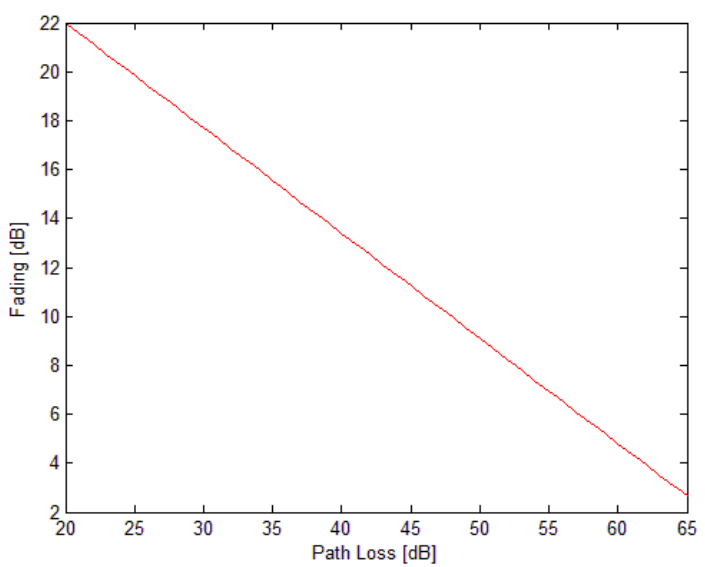

Gambar 6. Nilai Small-scale Fading vs Path loss

Tabel 1.

Daftar Frekuensi

\begin{tabular}{ll}
\hline \hline Deskripsi & Frekuensi \\
\hline Implant & $402-405 \mathrm{MHz}$ \\
On-body & $13.5 \mathrm{MHz}$ \\
On-body & $5-50 \mathrm{MHz}$ \\
On-body & $400 \mathrm{MHz}$ \\
On-body & $600 \mathrm{MHz}$ \\
On-body & $900 \mathrm{MHz}$ \\
On-body & $2.4 \mathrm{GHz}$ \\
On-body & $3.1-10.6 \mathrm{GHz}$ \\
\hline
\end{tabular}


Tabel 2.

Daftar Skenario dan Deskripsinya

\begin{tabular}{llc}
\hline \hline Skenario & Deskripsi & Model Kanal \\
\hline 1 & $\begin{array}{l}\text { Permukaan tubuh ke permukaan } \\
\text { tubuh (LOS) }\end{array}$ & MK1 \\
2 & $\begin{array}{l}\text { Permukaan tubuh ke permukaan } \\
\text { tubuh (NLOS) }\end{array}$ & MK1 \\
3 & $\begin{array}{l}\text { Permukaan tubuh ke node eksternal } \\
\text { (LOS) }\end{array}$ & MK2 \\
4 & $\begin{array}{l}\text { Permukaan tubuh ke node eksternal } \\
\text { (LOS) }\end{array}$ & MK2 \\
\hline \hline
\end{tabular}

Tabel 3.

Parameter Path loss Skenario 1

\begin{tabular}{cc} 
& Parameter Path loss Skenario 1 \\
\hline \hline Model Path loss & $P L[d B]=a \log _{10}(d)+b+c+N$ \\
\hline $\mathrm{a}$ & 6.6 \\
$\mathrm{~b}$ & 36.1 \\
$\mathrm{c}$ & -7.5 \\
$\sigma_{\mathrm{N}}$ & 3.80 \\
\hline \hline
\end{tabular}

Tabel 4.

Parameter Path loss

\begin{tabular}{cc}
\hline \hline Model & \\
Path loss & $P L_{d B}=-10 \log _{10}\left(P_{0} e^{-m_{0} d}+P_{1}\right)+\sigma_{p} n_{p}$ \\
\hline $\mathrm{P}_{0}(\mathrm{~dB})$ & -25.8 \\
$\mathrm{~m}_{0}$ & 2.0 \\
$(\mathrm{~dB} / \mathrm{cm})$ & \\
$\mathrm{P}_{1}(\mathrm{~dB})$ & -71.3 \\
$\sigma_{\mathrm{p}}(\mathrm{dB})$ & 3.6 \\
\hline \hline
\end{tabular}

Tabel 5.

Parameter Small-scale Fading

\begin{tabular}{cc}
\hline \hline Model Path loss & $K_{d B}=K_{0}-m_{K} P_{d B}+\sigma_{K} n_{K}$ \\
\hline $\mathrm{K}_{0}(\mathrm{~dB})$ & 30.6 \\
$\mathrm{~m}_{\mathrm{K}}$ & 0.43 \\
$\sigma_{\mathrm{K}}(\mathrm{dB})$ & 3.4 \\
\hline \hline
\end{tabular}

Tabel 6.

Nilai MSE dari Jenis Fungsi untuk skenario

\begin{tabular}{cc}
\hline \hline Jenis Fungsi & Nilai $M S E$ \\
\hline BETA & 0,002741 \\
Eksponensial & 0,094266 \\
Gamma & 0,016638 \\
Lognormal & 0,037997 \\
Normal & 0,002797 \\
Triangular & 0,004446 \\
Weibull & 0,005517 \\
\hline \hline
\end{tabular}

Tabel 7.

Nilai MSE dari Jenis Fungsi untuk skenario 2

\begin{tabular}{cc}
\hline \hline Jenis Fungsi & Nilai MSE \\
\hline BETA & 0,021460 \\
Eksponensial & 0,444781 \\
Gamma & 0,369958 \\
Lognormal & 0,407024 \\
Normal & 0,285980 \\
Triangular & 0,293839 \\
Weibull & 0,292966 \\
\hline \hline
\end{tabular}

Tabel 8.

Nilai Path loss Skenario 3 \& 4

\begin{tabular}{ccc}
\hline \hline Jarak & Orientasi Tubuh & $\begin{array}{c}\text { Rata- rata nilai } \\
\text { Path loss }(\mathrm{dB})\end{array}$ \\
\hline \multirow{3}{*}{1} & 0 & 57,2 \\
& 90 & 57,5 \\
& 180 & 66,5 \\
& 270 & 58,2 \\
2 & 0 & 60,4 \\
& 90 & 63,4 \\
& 180 & 66,3 \\
& 270 & 63,2 \\
3 & 0 & 61,7 \\
& 90 & 63,1 \\
& 180 & 65,6 \\
& 270 & 65,0 \\
4 & 0 & 63,3 \\
& 90 & 65,1 \\
& 180 & 66,6 \\
\hline \hline
\end{tabular}

Tabel 9.

Jenis Fungsi Distribusi

\begin{tabular}{ccl}
\hline \hline Jarak & Orientasi Tubuh & Jenis Fungsi \\
\hline \multirow{3}{*}{1} & 0 & BETA $(1.07,0,913)$ \\
& 90 & Erlang $(0.973,3)$ \\
& 180 & Normal $(62.4,1.66)$ \\
& 270 & BETA $(0.926,1.11)$ \\
\multirow{2}{*}{2} & 0 & Triangular $(55,56.8,60.9)$ \\
& 90 & Lognormal $(2.36,2.2)$ \\
& 180 & Triangular $(59,61.4,67)$ \\
& 270 & Weibull $(3.76,1.77)$ \\
3 & 0 & Triangular $(56,60.2,62)$ \\
& 90 & BETA $(0.909,0.645)$ \\
& 180 & BETA $(0.672,0.442)$ \\
& 270 & Gamma $(1.522,2.42)$ \\
4 & 0 & BETA $(0.835,0.77)$ \\
& 90 & Triangular $(55,61.6,66)$ \\
& 180 & Lognormal $(3.54,2.69)$ \\
\hline \hline
\end{tabular}

1. Memiliki kemampuan heterogen dan didesain agar tidak mengganggu pengguna (host). Karena itu, sensor pada BAN memiliki bentuk, sumber tenaga, memory, penghitungan, dan kemampuan komunikasi yang terbatas jika dibandingkan dengan node sensor generic, sehingga mengharuskan BAN untuk menggunakan node dalam jumlah banyak untuk mengambil data kesehatan pasien yang handal dan tanpa kesalahan.

2. Sensor memungkinkan untuk di implant atau dipakai di alam, sensor yang diimplan harus memenuhi persyaratan keamanan, keselamatan, dan ketahanan.

3. Sensor didesain untuk mengukur beberapa rangsangan dari lingkungannya (tubuh manusia).

4. Sensor didesain untuk kondisi yang ekstrim seperti pada perubahan suhu dan pada kondisi berair atau asam.

5. Sensor berkemungkinan ditenagai menggunakan sumber tenaga seperti gerakan tubuh, panas tubuh, dan biofuels 
seperti gula darah.

Seperti contoh, alat pacu jantung yang diimplan harus beroperasi pada tingkat keasaman cairan tubuh dan beroperasi menggunakan tenaga yang berasal dari panas tubuh.

Tiap BAN memiliki satuan control yang disebut base station, yang mana mengambil dan memproses data dari tiap node sensor secara berkala. Ukuran jaringan BAN bisa bervariasi mulai dari jaringan kecil dengan beberapa node sampai ke jaringan besar dengan ratusan node. Dengan kata lain, BAN dapat digunakan untuk berbagai macam aplikasi, termasuk manajemen kesehatan olahraga, pusat kesehatan dirumah untuk orang tua, dan penanganan pasca-operasi.

BAN terdiri dari dua komponen: (1) node sensor, yang mana memiliki kemampuan penghitungan yang rendah; dan (2) base station, yang mana merupakan alat penghitung berkemampuan tinggi seperti smartphone atau PDA. Pada BAN, tiap komponen berkomunikasi satu sama lain melalui kanal wireless, karena jika menggunakan kabel antar sensor akan mengganggu. Sensor komunikasi diasumsikan menjadi handal dan tiap sensor di sinkronisasikan berdasarkan waktu, menggunakan skema berbasis waktu kedatangan paket. Tiap node di BAN yang berdekatan dapat berkomunikasi melalui jaringan one-hop (dipengaruhi oleh jangkauan komunikasi).

Penjelasan mengenai WBAN dapat dilihat secara lengkap pada referensi [6].

\section{B. Definisi dan Gambaran Umum}

Model kanal diperlukan untuk mengevaluasi kinerja dari lapisan fisik yang berbeda. Tujuan utama dari model kanal ini adalah untuk perbandingan dari usulan yang berbeda. Model kanal tidak digunakan untuk mendapatkan informasi kinerja yang absolut dari berbagai lingkungan atau postur tubuh. Daftar frekuensi yang dapat diukur ditunjukkan pada tabel 1.

Pada tugas akhir ini, frekuensi yang digunakan adalah 2.4 $\mathrm{GHz}$ (Bluetooth) sehingga pengukuran yang dapat dilakukan adalah pengukuran On-Body baik antar permukaan tubuh maupun dari tubuh ke node eksternal.

Langka utama dalam pengembangan WBN adalah karakterisasi dari propagasi gelombang elektromagnetik dari perangkat yang dekat atau didalam tubuh. Kompleksitas dari struktur organ manusia dan bentuk tubuh membuatnya sangat sulit untuk mengukur path loss sederhana dari model WBAN. Antena dari aplikasi WBAN diletakkan pada atau didalam tubuh, model kanal dari WBAN harus mempertimbangkan pengaruh dari tubuh terhadap propagasi radionya.

Terdapat 3 tipe node yang didefinisikan sebagai berikut:

1. Node Implan: node yang diletakkan didalam tubuh manusia. Kemungkinan bisa diletakkan dibawah kulit ataupun jauh didalam organ tubuh.

2. Node permukaan tubuh: node yang diletakkan pada permukaan kulit manusia atau paling jauh sekitar 2 centimeter diatas kulit.

3. Node eksternal: node yang tidak bersentuhan dengan kulit manusia (diatas 2 cetimeter sampai 5 meter dari tubuh)

Untuk komunikasi pada permukaan tubuh, jarak antar node pengirim dan penerima harus mempertimbangkan jarak sekeliling tubuh jika pengirim dan penerima diletakkan tidak pada sisi yang sama. Hal ini mengakibatkan difraksi gelombang yag merambat harus dipertimbangkan pula. Untuk node komunikasi eksternal, jarak antara penerima dan pengirim harus jauh dari tubuh manusia dengan jarak maksimum 5 meter.

Batas maksimum daya yang digunakan untuk perangkat medis on-body ditentukan oleh regulasi regional dan internasional yang dideskripsikan sebagai berikut:

1. ETSI (European Telecommunication Standarts Institute): daya output maksimum adalah $25 \mathrm{uW}$ ERP

2. FCC dan ITU-R: daya output maksimum adalah $25 \mathrm{uW}$ EIRP atau $2.2 \mathrm{~dB}$ lebih rendah dari tingkat ERP.

Frekuensi yang digunakan untuk implan harus memiliki frekuensi 402-405 MHz. struktur dari model kanal untuk skenario pada permukaan tubuh dan implant tidaklah sama. Model kanal pada perangkat yang di implan sangatlah berbeda.

\section{SKENARIO SIMULASI}

Pada tugas akhir ini, frekuensi yang digunakan adalah 2.4 $\mathrm{GHz}$ (Bluetooth) yang mana hanya dapat digunakan pada sistem komunikasi WBAN on-body. Akan tetapi, skenario yang digunakan dalam simulasi MATLAB yang akan dibuat diperluas lagi menjadi beberapa bagian yang dideskripsikan pada tabel dibawah ini.

Jarak maksimal dari perangkat eksternal adalah 5 meter. Hubungan komunikasi yang memungkinkan dideskripsikan pada gambar 2 .

\section{A. Permukaan Tubuh Ke Permukaan Tubuh (Los)}

Bentuk rumus Path loss yang digunakan adalah rumus yang bergantung pada fungsi jarak sehingga menjadi:

$P L[d B]=a \log _{10}(d)+b+c+N$

Dimana:

PL : Path loss

a dan $\mathrm{b}$ : koefisien linear

d : : jarak Tx dan Rx dalam mm

$\mathrm{N}$ : variable fungsi normal dengan standar deviasi $\sigma_{\mathrm{N}}$

Penjelasan dan nilai dari parameter path loss yang digunakan didapatkan dari paper referensi [2].

\section{B. Permukaan Tubuh Ke Permukaan Tubuh (NLOS)}

Bentuk rumus path loss yang digunakan bergantung kepada nilai peluruhan eksponensial pada perimeter tubuh.

\section{$P L_{d B}=-10 \log _{10}\left(P_{0} e^{-m_{0} d}+P_{1}\right)+\sigma_{p} n_{p}$}

Pada skenario 2 disini dibahas mengenai antara permukaan tubuh dan permukan tubuh yang tidak LOS (line of sight) oleh karena itu, nilai small-scale fading perlu diperhitungkan juga. Sehingga, rumus dari fading adalah:

$K_{d B}=K_{0}-m_{K} P_{d B}+\sigma_{K} n_{K}$

Dimana:

$\mathrm{K}_{0}$ : pengukuran data untuk faktor $\mathrm{K}$ untuk path loss rendah $\mathrm{M}_{\mathrm{K}}$ : penurunan dari korelasi linear antara path loss dan faktor $\mathrm{K}$

$\mathrm{P}_{\mathrm{dB}}$ : path loss dalam $\mathrm{dB}$ 
$\sigma_{\mathrm{K}}$ : varian lognormal dari data pengukuran antara path loss dan faktor $\mathrm{K}$

$\mathrm{N}_{\mathrm{K}}$ : mean unit dan varian dari variable acak Gauss

Selanjutnya adalah penjelasan tentang parameter-parameter yang digunakan dalam rumus path loss

Penjelasan dan nilai dari parameter path loss yang digunakan didapatkan dari paper referensi [3]

\section{Permukaan Tubuh Ke Node Eksternal (LOS \& NLOS)}

Bentuk rumus path loss yang digunakan adalah:

$$
\begin{array}{ll}
P L(t)=P_{t x}- & P_{r x}(t)+G_{a m p l i f i e r s}-L_{c a b l e}+10 \log _{10}(r) \\
\text { Dimana: } & \\
\text { Ptx } & : \text { daya yang ditransmisikan } \\
\text { Prx }(\mathrm{t}) & : \text { daya RMS yang diterima pada waktu } \mathrm{t} \\
\text { Gamplifiers } & \text { : gain amplifier } \\
\text { Lcable } & : \text { Loss kabel } \\
\text { R } & : \text { jarak antara antenna pengirim dan penerima } \\
\text { Dengan ketentuan: } & \\
\text { Ptx } & : 0 \mathrm{dBm} \\
\text { Gamplifiers } & : \text { LNA + Pre-amp }=55 \mathrm{~dB} \\
\text { Lcable } & : 10 \mathrm{~dB} \\
\mathrm{r} & : 1,2,3,4 \mathrm{~m}
\end{array}
$$

Karena sensitivitas antena penerima terbatas, nilai path loss harus kurang dari $76 \mathrm{~dB}$ untuk membedakan sinyal yang ditransmisikan dengan noise.

\section{HASIL DAN ANALISA}

\section{A. Permukaan Tubuh Ke Permukaan Tubuh (LOS)}

Hasil simulasi yang didapat adalah nilai path loss dalam $\mathrm{dB}$ yang mana diukur berdasarkan perbedaan jarak antara node pengirim dan node penerima.

Bisa dilihat pada gambar 4 pada setiap jarak yang diukur, 4 sampel kanal diambil yang mana data lengkapnya dapat dilihat di lampiran. Dari hasil path loss ini kita dapat mengetahui bentuk kanalnya dengan mencari fungsi yang memiliki square error yang rendah yang memenuhi data path loss diatas. Dari semua pendekatan yang dilakukan dapat dibentuk sebuah tabel yang membandingkan nilai MSE dari masing-masing fungsi yang digunakan.

Dari tabel 6 dapat dilihat bahwa jenis fungsi yang memiliki nilai MSE terkecil adalah fungsi BETA. Akan tetapi dapat didekati menggunakan fungsi Normal, Triangular, dan Weibull karena ketiga fungsi tersebut memiliki nilai MSE yang tidak jauh berbeda dengan nilai MSE dari fungsi BETA.

\section{B. Permukaan Tubuh Ke Permukaan Tubuh (NLOS)}

Hasil simulasi yang didapat adalah nilai Path loss dalam dB yang mana berpengaruh terhadap jarak yang tidak LOS (line of sight) dan perbandingan antara path loss dengan small scale fading untuk membuktikan bahwa nilai fading berpengaruh terhadap path loss.

Gambar 6 adalah perbandingan nilai fading dengan nilai path loss dan kita dapat mengetahui bahwa saat nilai fading tinggi nilai path loss nya rendah dan ketika nilai fading nya rendah maka nilai path loss nya tinggi. Hasil plot nilai path loss pada gambar 5 didapatkan dari persamaan (3.2) yang kemudian dibandingkan dengan nilai small scale fading yang didapatkan dari persamaan (3.3). Dari semua pendekatan yang dilakukan dapat dibentuk sebuah tabel yang membandingkan nilai MSE dari masing-masing fungsi yang digunakan. Pendekatan dilakukan dengan menggunakan software ARENA yang mana akan menghitung nilai MSE dari tiap-tiap jenis fungsi yang ada.

Dari tabel 7 dapat dilihat bahwa jenis fungsi yang memiliki nilai MSE terkecil adalah fungsi BETA. Jika dilihat dari nilai MSE tiap jenis fungsi, tidak ada yang memiliki nilai MSE yang mendekati fungsi BETA.

\section{Permukaan Tubuh Ke Node Eksternal (LOS \& NLOS)}

Hasil simulasi yang didapat pada sub-bab ini adalah nilai path loss antara node yang berada di permukaan tubuh manusia dengan node eksternal yang jaraknya berubah dari 1 , 2, 3 dan 4 meter. Dan orientasi tubuh berubah berdasarkan sudut dari 00, 900, 1800 dan 2700 dimana 00 adalah posisi LOS (line of sight) dan 900 adalah ketika posisi tubuh manusia menghadap ke kanan dan seterusnya. Dari tiap jarak dan orientasi dilakukan simulasi selama 10 detik untuk mengetahui bentuk kanalnya sehingga dapat diprediksi juga jenis fungsinya.

Tabel 8 menjelaskan tentang rata-rata nilai path loss dari tiap tiap orientasi tubuh yaitu 00, 900, 1800 dan 2700. Nilai rata-rata tersebut didapatkan dari pengambilan data selama 10 detik dengan laju 1 sampel per detik sehingga didapatkan 10 nilai path loss untuk masing-masing jarak dan orientasi tubuh.

Dari tabel 9 dijelaskan jenis fungsi yang memiliki nilai MSE terendah untuk masing-masing kondisi. Akan tetapi, dari masing-masing kondisi tersebut memiliki kemungkinan untuk dapat diprediksi menggunakan jenis fungsi yang lain yang memiliki nilai MSE yang hampir sama dengan jenis fungsi yang ditulis diatas.

\section{KESIMPULAN}

Untuk mendapatkan bentuk kanal WBAN yang sesuai diperlukan perhitungan nilai path loss yang kemudian dicari bentuk fungsi distribusi yang mendekati bentuk nilai path loss tersebut atau memiliki nilai MSE (mean square error) yang rendah.

Rumus path loss yang digunakan pada WBAN berbeda dengan rumus path loss pada umumnya, karena rumus path loss pada WBAN digunakan untuk mengukur pada lingkungan tubuh manusia yang memiliki karakteristik yang berbeda-beda, unik, dan kompleks.

Bentuk Kanal yang paling mungkin digunakan pada WBAN adalah kanal yang memiliki nilai Mean Square Error (MSE) terendah. Namun, bentuk kanal tersebut dapat didekati menggunakan kanal lain apabila nilai MSE nya tidak jauh berbeda. 


\section{DAFTAR PUSTAKA}

[1] K. Yazdandoost and K. Sayrafian, "Channel Model for Body Area Network (BAN).” 15-08-0033-02-0006-draft-of-channel-model-forbody-area-network.

[2] Takahiro Aoyagi, Jun-ichi Takada, Kenichi Takizawa, Norihiko Katayama, Takehiko Kobayashi, Kamya Yekeh Yazdandoost, Huanbang $\mathrm{Li}$ and Ryuji Kohno, "Channel model for wearable and implantable WBANs." IEEE 802.15-08-0416-04-0006, November 2008.

[3] Guido Dolmans and Andrew Fort, "Channel models WBAN-Holst centre/IMEC-NL," IEEE 802.15-08-0418-01-0006, July 2008

[4] Dino Miniutti, Leif Hanlen, David Smith, Andrew Zhang, Daniel Lewis, David Rodda, Ben Gilbert, "Narrowband on body to off body channel characterization for BAN" IEEE 802.15-08-0559-00-0006, August 2008

[5] Attaphongse Taparugssanagorn, Alberto Rabbachin, Matti Hämäläinen, Jani Saloranta, and Jari Iinatti, "A Review of Channel Modelling for Wireless Body Area Network in Wireless Medical Communications.", University of Oulu : Finland.

[6] Sandeep K. S. Gupta, Tridib Mukherjee, and K. Kumar V., ,"Body Area Networks safety, Security, and Sustainability.", Cambridge 